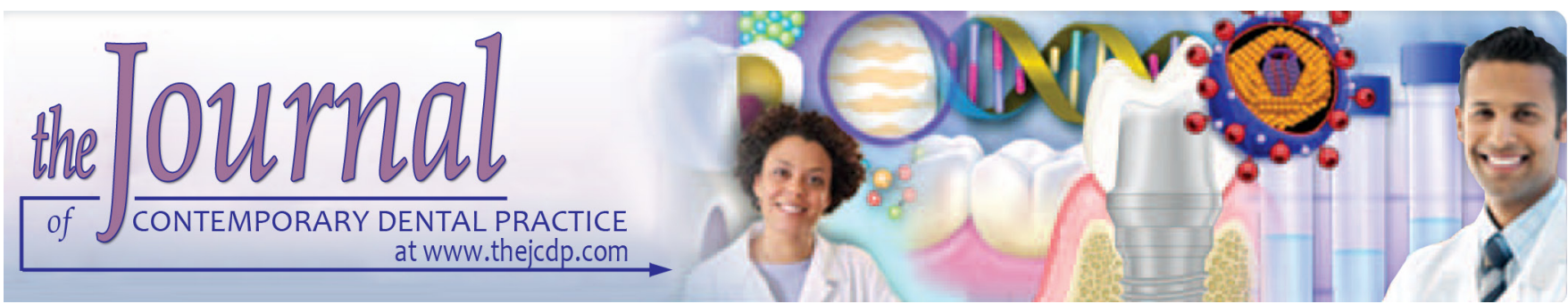

\title{
Human Development Index, Ratio of Dentists and Inhabitants, and the Decayed, Missing or Filled Teeth Index in Large Cities
}

\author{
${ }^{1}$ Fabio A Pereira, ${ }^{1}$ Iranilda A de Mendonça, ${ }^{1}$ Renata I Werneck, ${ }^{1}$ Simone T Moysés, ${ }^{2}$ Marilisa CL Gabardo, \\ ${ }^{1}$ Samuel J Moysés
}

\begin{abstract}
Aim: This study aimed to investigate the associations between human development and the demographic ratio of dentists with the prevalence of dental caries at 12 years of age in large Brazilian cities.

Materials and methods: Data were collected from 27 state capitals, Secondary databases were used: the municipal human development index (MDHI); the ratio of dentists qualified to exercise their profession according to the number of inhabitants; and the decayed, missing or filled teeth index (DMFT). Pearson correlation coefficient analysis and multiple logarithmic regression analysis were performed.
\end{abstract}

Results: The MDHI showed a strong correlation with DMFT and explained $48.1 \%$ of the variation in the cities. The ratio of dentists to the number of inhabitants displayed an insignificant, weak correlation with the variations in the DMFT.

Conclusion: Social factors strongly influence the oral health/ disease process in Brazilian capitals, thus actions are needed for the promotion of health at more distal, or structural levels that modify the environment, thus enabling healthier choices for individuals. These results challenge traditional beliefs that only the ratio of professional dentists to inhabitants and the provision of dental services have beneficial effects on the prevention and control of oral health problems.

Clinical significance: The prevalence of dental caries is strongly correlated with social factors, as the MDHI.

Keywords: Dental caries, Epidemiology, Human development, Social determinants.

How to cite this article: Pereira FA, De Mendonça IA, Werneck RI, Moysés ST, Gabardo MCL, Moysés SJ. Human

\footnotetext{
${ }^{1}$ School of Life Sciences, Pontifícia Universidade Católica do Paraná, Rua Imaculada Conceição, Curitiba, Paraná, Brazil

${ }^{2}$ School of Health and Biological Sciences, Universidade Positivo, Rua Prof. Pedro Viriato Parigot de Souza, Curitiba, Paraná, Brazil

Corresponding Author: Marilisa CL Gabardo, School of Health and Biological Sciences, Universidade Positivo, Rua Prof. Pedro Viriato Parigot de Souza, Curitiba, Paraná, Brazil, Phone: +55 41 3526-5121, e-mail: marilisagabardo@gmail.com
}

Development Index, Ratio of Dentists and Inhabitants, and the Decayed, Missing or Filled Teeth Index in Large Cities. J Contemp Dent Pract 2018;19(11):1363-1369.

Source of support: Nil

Conflict of interest: None

\section{INTRODUCTION}

Over the last few decades, there has been a constant reduction in the mean prevalence of dental caries across different age groups in several countries, ${ }^{1-4}$ including Brazil, even though epidemiological gradients suggest inequalities in this decline. In the most recent Brazilian epidemiological survey on oral health, conducted by the Ministry of Health with national coverage (a project called SB Brazil 2010), ${ }^{5}$ it was found that the mean DMFT in the 12-year-old population was not homogeneous. There was a remarkable gradient between the five regions of the country, with the South and the Southeast presenting the best results in contrast to the North, Northeast, and Mid-West. ${ }^{5}$

The polarization of dental caries-a phenomenon discussed in the literature-in which approximately 20\% of the population is responsible for $60 \%$ of the disease burden, ${ }^{6}$ does not explain the differences found. This polarization should hypothetically manifest in all macroregions, and therefore does not depend only on the biological characteristics of individual residents in each region. Presumably, there would also be certain social determinants, such as aspects related to human development and the structural sustainability of each macroregion, which may reflect the inequalities in the health-disease process and the epidemiological situation.

Therefore, the heterogeneous distribution of caries in the 12-year-old population in different regions in Brazil would not only reflect mathematical disparities, expressed as cold empirical values but would also 
represent systematic social inequalities, including inequalities deemed socially unjust and avoidable. Such inequalities are reflected in the worse conditions of life and health for millions of young people in Brazil. This statement is based on the United Nations Development Programme Report, ${ }^{7}$ which, despite recent progress, still places Brazil in 12th place among the world's most unequal countries in terms of the socioeconomic factor of the income distribution.

Among the various theoretical-methodological approaches, one method for assessing the social determinants of health/disease progress in a population is to correlate the human development index (HDI) with indicators of health. The HDI was created to offer a counterpoint to the gross domestic product (GDP) per capita, which only considers the economic dimension of development. The three pillars that constitute the HDI are health, education, and income. ${ }^{8,9}$ When measured at the municipal level; this synthetic index is presented as the MHDI.

On the contrary, it is permissible to question the possible correlation between the provision of dental care to the population - translated in terms of professionals qualified to practice and the health/oral disease indicators. ${ }^{10,11}$ What does reality indicate regarding the influence of interventions administered by healthcare professionals (including dentists) on reducing the social inequalities in health and improving the epidemiological indicators?

Some recommendations for answering this question have been proposed in a recently published report "Working for Health Equity: The Role of Health Professionals." This report focuses on the actions and strategies of health care professionals that can be incorporated into a health care system. All professionals involved in primary care should address the needs of families in the context of their environment and life experience. $^{10}$

The report "Profile and Trends of Brazilian Dentists" published in $2010^{12}$ indicated that Brazil has one of the largest numbers of dentists in the world; $43.1 \%$ of the total number of qualified professionals in the country were located in the state capitals in the year 2010. One could question whether this phenomenon would have any effect on the prevalence of dental caries - measured by the DMFT index in 12-year-old in Brazilian state capitals, and how this issue is correlated with the indicators of quality of life-measured by the MHDI in these capitals.

Based on these problems, in the present study, we aimed to explore the associations between the independent variables MHDI and inhabitants/dentist ratio and the dependent variable mean DMFT index in 12-years-old in 27 Brazilian state capitals, in order to verify which of these independent variables would provide greater explanatory power based on the variation in the dependent variable in these 27 large cities.

\section{MATERIALS AND METHODS}

In this ecological-type study, secondary data were processed to assess the correlation of the indicators of municipal human development and ratio of dentists per capita with the DMFT in 27 Brazilian capitals.

The MHDI was used as an independent variable of human development. The HDI is useful to determine the level of well-being of a population and can be used as a proxy estimate of life conditions and the social determinants of health in a reliable manner. It is fully plausible to assume that the process of illness due to caries, in theory, should be correlated with the indicators of material conditions and the quality of life of a given population. For example, Antunes et al. ${ }^{9}$ demonstrated the association between worse levels of oral health and less favorable socioeconomic conditions.

The MHDI of the capital cities was collected by referring to the Atlas of Human Development in Brazil 2013, available at the portal of the United Nations Development Programme, ${ }^{7}$ which contains data for the year 2010. The MHDI is a variation of the HDI on a municipal scale and is composed of three dimensions considered to be essential to people's lives: income, longevity, and education. Regarding income, the international comparative criterion, purchasing power parity (PPP), was used, i.e., the municipal income per capita in PPP dollars. For longevity, the life expectancy at birth for the year of study was considered. For education, two indicators with different weights were considered the literacy rate of people aged $>15$ years, with a weight of two, and the gross rate of schooling frequency, with a weight of one. The arithmetic mean was then calculated between the three dimensions, yielding a number between zero and one; an index closer to 1 represents a better result. ${ }^{8,9}$

The ratio between dentists and inhabitants was calculated from data available at the Federal Council of Dentistry $(\mathrm{CFO})^{13}$ and from the IBGE census for $2010,{ }^{14}$ by estimating the ratio between the number of inhabitants of each capital and the number of dentists enrolled and active in the CFO in 2010, ${ }^{13}$ which was the second independent variable.

The DMFT was used as the dependent variable, and these data were obtained from the last national oral health epidemiological survey. ${ }^{5}$ 
Table 1 presents the data from 27 Brazilian capitals with their respective dependent (DMFT) and independent (inhabitants/dentist ratio and MHDI) variables used in the study.

Based on the objectives, it was statistically processed the data. To test the effects of the outcome variable, DMFT, according to the independent variables, MHDI and inhabitants/dentist ratio, initially was tested the normality of the distribution in the databases used, while considering that ${ }^{27}$ capital cities were assessed, which did for fulfill the criterion of $\mathrm{n} \geq 30$ for a normal asymptotic distribution. Hence, it was used the Kolmogorov-Smirnov normality test, assuming $\mathrm{p} \leq 0.05$. Both, independent and dependent variables, showed a normal distribution. Thereafter, descriptive statistics of the variables, accompanied by the respective frequency histograms, were calculated.

To assess the strength of the correlations between the variables, Pearson correlation matrix was defined. Moreover, it was performed multiple linear regression

Table 1: Brazilian capitals and their DMFT, inhabitants/dentist ratio, and MHDI values

\begin{tabular}{llll}
\hline Capital & DMFT & $\begin{array}{l}\text { Inhabitants/ } \\
\text { dentist ratio }\end{array}$ & MHDI \\
\hline Aracaju & 1.13 & 396 & 0.77 \\
Belém & 2.45 & 978 & 0.746 \\
Belo Horizonte & 1.1 & 175 & 0.81 \\
Boa Vista & 2.83 & 637 & 0.752 \\
Brasília & 1.14 & 434 & 0.824 \\
Campo Grande & 1.65 & 472 & 0.784 \\
Cuiabá & 2.4 & 414 & 0.785 \\
Curitiba & 1.53 & 316 & 0.823 \\
Florianópolis & 0.77 & 230 & 0.847 \\
Fortaleza & 1.44 & 625 & 0.754 \\
Goiânia & 1.76 & 310 & 0.799 \\
João Pessoa & 2.78 & 384 & 0.763 \\
Macapá & 2.46 & 996 & 0.733 \\
Maceió & 2.46 & 486 & 0.721 \\
Manaus & 2.34 & 721 & 0.737 \\
Natal & 2.08 & 391 & 0.763 \\
Palmas & 2.35 & 507 & 0.788 \\
Porto Alegre & 1.49 & 299 & 0.805 \\
Porto Velho & 4.15 & 611 & 0.736 \\
Recife & 1.66 & 429 & 0.772 \\
Rio Branco & 2.63 & 1318 & 0.727 \\
Rio de Janeiro & 1.4 & 404 & 0.799 \\
Salvador & 1.07 & 560 & 0.759 \\
São Luís & 2.66 & 594 & 0.768 \\
São Paulo & 1.41 & 406 & 0.845 \\
Teresina & 1.55 & 529 & \\
Vitória & 1.28 & 192 & \\
\hline Sourcs: & & \\
\hline
\end{tabular}

Sources: Brasil5; PNUD7; CFO13; IBGE14 analysis to assess the level of significance of both the independent variables with the dependent variable.

The final fit of the model was performed, while considering that the linear regression model does not realistically express the epidemiological impossibility of a DMFT curve on the $\mathrm{X}$-axis, with a prevalence tending towards zero, as the values of MHDI increase in the $y$-axis. In fact, the behavior of the mean DMFT resembles a curve with a hyperbole branch, with smoothed effects along the $x$-axis. This behavior of the variable DMFT can be thought of as a Nerlove distributed lag model. ${ }^{15}$ In this model, the expectation of the prevalence of dental caries in a population should be corrected, given the fact that this prevalence does not reach absolute zero, i.e., allowing the assumption of a non-linear model with a logarithmic function.

\section{RESULTS}

With the use of the Pearson's correlation matrix and scatter diagrams between the variables, the values obtained showed a strong negative correlation between the dependent variable DMFT and the independent variable MHDI (-0.659), which was statistically significant ( $p \leq 0.01)$. A moderate positive correlation was also observed between the independent variable inhabitants/ dentist ratio and DMFT (0.511), with $p \leq 0.01$.

The two independent variables MHDI and inhabitants/ dentist ratio were entered into the multiple linear regression model (Table 2), which was coherent and useful for testing the consistency of two theoretical models: the social determinant of the disease, through the MHDI and DMFT, and the association between the density of dental professionals (inhabitants/dentist ratio) and DMFT. The variations in the inhabitants/dentist ratio were not significant in explaining the variations in the DMFT; hence, only the variable MHDI indicated statistically significant results, and showed a negative correlation-i.e., the relative increment in MHDI matches a corresponding decrease in the mean DMFT in the capital cities.

Given the heteroscedasticity presented, and the strong dispersion of the data observed, two steps were followed. First, an analysis of the residuals (Graph 1) was performed, followed by an adjustment of the regression model for a non-linear approach in the logarithm. Thus, in order to adjust the model, based on the assumption that the dependent variable DMFT (which represents the mean prevalence of caries in the population) would not be zero, even when the MHDI increases towards the upper limit, we applied the model with the logarithm of the dependent variable as a function of the independent 
Table 2: Coefficients of the multiple linear regression model of the DMFT according to the MHDI and the inhabitants/dentist ratio

\begin{tabular}{|c|c|c|c|c|c|c|}
\hline \multicolumn{7}{|c|}{ Coefficients } \\
\hline \multirow{2}{*}{$\begin{array}{l}\text { Multiple linear } \\
\text { regression model }\end{array}$} & \multicolumn{2}{|c|}{ Non-standardized coefficients } & \multirow[b]{2}{*}{$\mathrm{t}$} & \multirow[b]{2}{*}{ Sig. } & \multicolumn{2}{|c|}{$95.0 \%$ confidence interval for $B$} \\
\hline & $\mathrm{B}$ & Standard error & & & Lower limit & Upper limit \\
\hline 1 (Constant) & 12.086853 & 4.028093 & 3.000639 & 0.006196 & 3.773276 & 20.40043 \\
\hline Inhabitants/ & 0.0001740 & 0.000667 & 0.260814 & 0.796461 & $-0,001203$ & 0.001552 \\
\hline dentist ratio & & & 7 & 1 & 0,001203 & - \\
\hline MHDI & - & 4.853561 & - & 0.011947 & - & - \\
\hline & -13.201350 & 4.853561 & -2.719930 & 0.011947 & $-23,21861$ & -3.184091 \\
\hline
\end{tabular}

Dependent variable: mean DMFT

Table 3: Coefficients of the model adjusted for the multiple regression of the logarithm of the DMFT according to the MHDI and the inhabitants/dentist ratio

\begin{tabular}{|c|c|c|c|c|c|c|}
\hline \multicolumn{7}{|c|}{ Coefficients } \\
\hline \multirow{2}{*}{$\begin{array}{l}\text { Multiple logarithmic } \\
\text { regression }\end{array}$} & \multicolumn{2}{|c|}{ Non-standardized coefficients } & \multirow[b]{2}{*}{$t$} & \multirow[b]{2}{*}{ Sig. } & \multicolumn{2}{|c|}{$95.0 \%$ confidence interval for $B$} \\
\hline & $B$ & Standard error & & & Lower limit & Upper limit \\
\hline 1 (Constant) & -0.594 & 0.3922 & -1.5137 & 0.1432 & -1.4032 & 0.2158 \\
\hline LOG/MHDI & 0.1081 & 2.1899 & -2.3143 & 0.0295 & -9.5876 & -0.5483 \\
\hline $\begin{array}{l}\text { LOG/ratio between } \\
\text { inhabitants and } \\
\text { dentists }\end{array}$ & 0.054 & 0.2109 & 0.5123 & 0.6131 & -0.3273 & 0.5434 \\
\hline
\end{tabular}

Dependent variable: LOG/DMFT

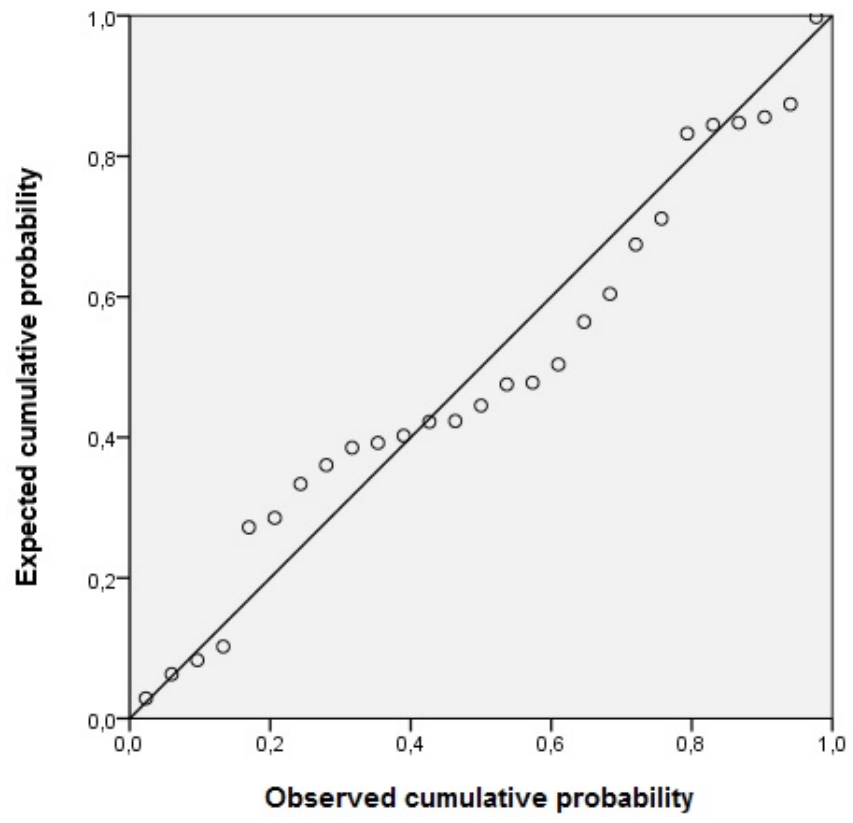

Graph 1: Graphical analysis of the residuals for the multiple linear regression of the DMFT according to the MHDI

variables, thus obtaining a curve in the shape of a hyperbola.

As shown in Table 3, and similar to that noted in the multiple linear regression model, the variable inhabitants/ dentist ratio was not statistically significant in the $\operatorname{logarithm}(\mathrm{p}=0.613)$. In other words, we confirmed that the variations in inhabitants per dentist are not significant in explaining the variations in the DMFT, with $p \leq 0.05$. On the other hand, the correlation between MHDI and the DMFT in the logarithm was $69.4 \%$, and the coefficient

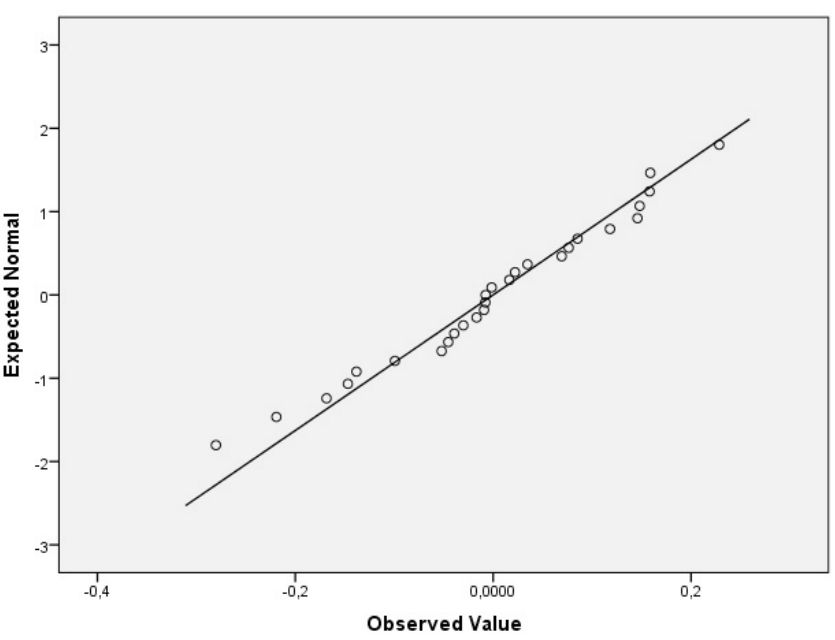

Graph 2: Graphical analysis of the residuals of the final model adjusted for multiple regression on the logarithm of the DMFT according to the MHDI

of determination showed that variations in MHDI explain $48.1 \%$ of the variation in the DMFT.

The final adjusted model, with the residual analysis, is presented in Table 4 and Graph 2. It was decided to withdraw the variable inhabitants/dentist ratio when processing the logarithm of the DMFT as a function only of MHDI, as the variable inhabitants/dentist ratio was found to be insignificant in the logarithm $(p=0.613)$. This model estimates the mean value of the DMFT in the capital cities; however, the significance of the variable MHDI in the estimation of the DMFT had $p \leq 0.01$. The significance of the correlation was probably not higher due to the large variations that exist in the DMFT among the capital 
Table 4: The coefficient of the final adjusted model as a logarithm of the DMFT according to the MHDI

\begin{tabular}{|c|c|c|c|c|c|c|}
\hline \multicolumn{7}{|c|}{ Coefficients } \\
\hline \multirow{2}{*}{$\begin{array}{l}\text { Model Log DMFT as a } \\
\text { function of MHDI }\end{array}$} & \multicolumn{2}{|c|}{ Non-standardized coefficients } & \multirow[b]{2}{*}{$t$} & \multirow[b]{2}{*}{ Sig. } & \multicolumn{2}{|c|}{$95.0 \%$ confidence interval for $B$} \\
\hline & $B$ & Standard error & & & Lower limit & Upper limit \\
\hline 1 (Constant) & -0.407 & 0.141 & -2.891 & 0.008 & -0.696 & -0.117 \\
\hline LOG/MHDI & -5.980 & 1.256 & -4.760 & 0.000 & -8.567 & -3.392 \\
\hline
\end{tabular}

Dependent variable: LOG/DMFT

cities; for example, four cities with an MHDI close to 0.75 presented a DMFT ranging between 1.44 and 2.83 .

\section{DISCUSSION}

In this study, the aim was to investigate the association between MHDI and the demographic ratio of dentists, with the prevalence of dental caries at 12 years of age in large Brazilian cities. The results showed that the independent variable, MHDI, had a strong negative correlation with the variable DMFT index in 12-year-old and could explain $48.1 \%$ of the variations in the DMFT when logarithmically correlated. In contrast, the variable inhabitants/dentist ratio presents a weak statistically insignificant positive correlation with the dependent variable, the DMFT, and this correlation was unable to explain the variations in the DMFT in the 27 Brazilian capital cities in both the multiple regression model and the logarithmic regression model.

The study had some limitations since only two independent variables were used to explain the variations in the DMFT. In addition, although the variable MHDI has a normal distribution, some cities with similar MHDI showed considerable variations in the DMFT. However, the methods used in the study are advantageous in terms of the robustness of the synthetic index HDI, which has been commonly used in the literature, and the use of a "modular reduction", to test and interpret the determinant factors for the prevalence of caries.

The finding that would be more apparent to those who advocate the positive influence of a high density of dentists in reducing the prevalence of dental caries in the population was not confirmed. The amount of dental care provision was not significantly associated with a reduction in the DMFT. In the agreement, a seminal work investigated the relative contribution of dental services to changes in the mean prevalence of dental caries in the 12-year-old population in 18 industrialized countries in the 1970s and early 1980s. ${ }^{16}$ Dental services explained 3\% of the variation in the level of caries, whereas general socioeconomic factors explained $65 \%$ of this variation. Moreover, the authors demonstrated that socioeconomic changes have a more critical role in the reduction of dental caries than the provision of dental services. ${ }^{16}$
A similar finding was found in 12-year-old school children in the state of Paraná when analyzed by controlled linear regression for socioeconomic indicators and water fluoridation. ${ }^{17}$ A recent study, even after controlling for individual and service area characteristics, indicated a significant geographic difference in accessibility, with impacts on oral health. ${ }^{18}$

In a study of the association between primary oral health care and municipal indicators, it was observed that cities with the worst socioeconomic conditions still offered services with mutilating characteristics and also found that municipalities with worst MHDI had a greater proportion of dental extractions compared to other procedures. In other words, municipalities with greater social deprivation, besides presenting a higher load of caries, also offered a mutilating care model, wherein interventions that were practiced mostly in past decades were preferably performed. . $^{19,20}$

The social gradient that reflects inequalities in general and in oral health suggest certain influences underlying psychosocial, economic, environmental, and political determinants. ${ }^{21}$ The dominant professional approach in dentistry seems unable to effectively reduce inequalities in oral health, most probably because this issue is not clearly included on the agenda, which is invariably guided by the clinical praxis of the market; instead it may even contribute to increasing such inequalities. ${ }^{22,23}$ Cangussu et al. ${ }^{24}$ pointed out the importance of access to dental services and social benefits to guarantee equity in oral health.

According to Narvai et al., ${ }^{6}$ there has been undeniable progress in the decrease in DMFT among young populations. However, a framework of inequality in the distribution of dental caries still exists, which can be explained by the poor living conditions of an important portion of the Brazilian population. The inequitable distribution of caries, which is socially determined and conditioned, partly reflects the results expressed in the human development report 2013. ${ }^{7}$ Brazil ranks 73rd in the HDI index. When this is adjusted for inequality, there is an overall decrease in the index by $27.2 \%$, and accordingly, Brazil drops to 85th place.

Considering the inequalities in oral health and the lack of contribution of the privately marketed odontocentered clinical model in its reduction, the literature argues for 
a more effective approach for professionals and for the formulation of public policies. A decisive performance in the social determinants of health would be needed, without being limited to actions directed only to individual behaviors; moreover, the repair of sequels that, alone, are not effective and may even contribute to extending such inequalities. ${ }^{22}$

The oral diseases share the same determinants and risk factors with major health problems. ${ }^{23,25}$ When properly integrated into primary health care, oral health teams in health systems have an important role in acting as lawyers, facilitators, and mediators of oral and general health, since these have common risk factors. In this sense, the action of the professional members of oral health teams can be more effective in the control and prevention of diseases.

\section{CONCLUSION}

Social factors strongly influence the oral health/disease process in Brazilian capitals, thus actions are needed for the promotion of health at more distal, or structural levels that modify the environment, thus enabling healthier choices for individuals. These results challenge traditional beliefs that only the ratio of professional dentists to inhabitants and the provision of dental services have beneficial effects on the prevention and control of oral health problems.

\section{CLINICAL SIGNIFICANCE}

The prevalence of dental caries is strongly correlated with social factors, as the MDHI.

\section{REFERENCES}

1. Lauris JR, da Silva Bastos R, de Magalhães Bastos J R. Decline in dental caries among 12-year-old children in Brazil, 19802005. Int Dent J 2012 Dec; 62(6): 308-414.

2. Irigoyen ME, Mejía-González A, Zepeda-Zepeda MA, Betancourt-Linares A, Lezana-Fernández AA, Álvarez-Lucas $\mathrm{CH}$. Dental caries in Mexican schoolchildren: a comparison of 1988-1989 and 1998-2001 surveys. Med Oral Patol Oral Cir Bucal 2012 Sep 1; 17(5): 825-832.

3. Elani HW, Harper S, Allison PJ, Bedos C, Kaufman JS. Socioeconomic inequalities and oral health in Canada and the United States. J Dent Res 2012 Sep; 91(9): 865-870.

4. Do LG. Distribution of caries in children: variations between and within populations. J Dent Res 2012 Jun; 91(6): 536-543.

5. Brasil. Ministério da Saúde. Projeto SB Brasil 2010. Pesquisa Nacional de Saúde Bucal - Principais Resultados. Brasília; 2012.

6. Narvai PC, Frazão P, Roncalli AG, Antunes JL. Dental caries in Brazil: decline, polarization, inequality and social exclusion. Rev Panam Salud Publica 2006 Jun; 19(6): 385-393.

7. Programa das Nações Unidas para o Desenvolvimento (PNUD). Relatório do Desenvolvimento Humano 2013.
A Ascensão do Sul: Progresso Humano num Mundo Diversificado [Internet]. New York: PNUD; 2013 [cited 2013 Dec 18]. 224 p. Available from: http://hdr.undp.org/sites/default/ files/hdr2013_portuguese.pdf

8. Instituto de Pesquisa Econômica Aplicada (IPEA). Índice de Desenvolvimento Humano Municipal Brasileiro [Internet]. Brasília: PNUD; 2013 [cited 2013 Dec 18]. 96 p. (Atlas do Desenvolvimento Humano no Brasil 2013). Available from: http://www.ipea.gov.br/agencia/images/stories/ PDFs/130729_AtlasPNUD_2013.pdf

9. Antunes JL, Peres MA, de Campos Mello TR, Waldman EA. Multilevel assessment of determinants of dental caries experience in Brazil. Community Dent Oral Epidemiol 2006 Apr; 34(2): 146-152.

10. Gabardo MCL, Ditterich RG, Cubas MR, Moysés ST, Moysés SJ. Inequalities in the workforce distribution in the Brazilian Dentistry. RGO Rev Gaúch Odontol 2017; 65(1): 70-76.

11. Pewa P, Garla BK, Dagli R, Bhateja GA, Solanki J. Utilization of dental services in public health center: dental attendance, awareness and felt needs. J Contemp Dent Pract 2015 Oct 1; 16(10):829-833.

12. Morita MC, Haddad AE, Araújo ME. Perfil atual e tendência do Cirurgião-Dentista Brasileiro [Internet]. Maringá: Dental Press; 2010 (cited 2013 Dec 10). 96 p. Available from: http://abeno.org. br/arquivos/downloads/download_20111202125600.pdf

13. Conselho Federal de Odontologia. Dados Estatísticos. 2001. Available at: http://cfo.org.br/servicos-e-consultas/dadosestatisticos/

14. Instituto Brasileiro de Geografia e Estatística. Sinopse do Censo Demográfico 2010. 2010. Avaliable at: http://www. pnud.org.br/IDH/Atlas2013.aspx?indiceAccordion=1\&li=li_ Atlas2013

15. Viana RL. Introdução à dinâmica não-linear e caos em Economia. 2012. Available from: http://dcm.ffclrp.usp.br/ jair/ listas/EDO-Economic-Model.pdf

16. Nadanovsky P, Sheiham A. Relative contribution of dental services to the changes in caries levels of 12-year-old children in 18 industrialized coutries in the 1970s and early 1980s. Community Dent Oral Epidemiol 1995 Dec; 23(6): 331-339.

17. Baldani MH, Narvai PC, Antunes JLF. Dental caries and socioeconomic conditions in the State of Paraná, Brazil, 1996. Cad Saude Publica 2002 May-Jun; 18(3): 755-763.

18. McKernan S, Kuthy RA, Hanley PF, Jones MP, Momany ET, McQuistan MR, Damiano PC. Geographic variation of dental utilization among low income children. Health Place 2015 Jul; 34: 150-156.

19. Fernandes LS, Peres MA. Association between primary dental care and municipal socioeconomic indicators. Rev Saude Publica 2005 Dec; 39(6): 930-936.

20. Moysés SJ, Moysés ST, McCarthy M, Sheiham A. Intra-urban differentials in child dental trauma in relation to Healthy Cities policies in Curitiba, Brazil. Health Place 2006 Mar; 12(1): 48-64.

21. Moysés SJ. Inequalities in oral health and oral health promotion. Braz Oral Res 2012; 26 (Supp 1): 86-93.

22. Watt R. From victim blaming to upstream action: tackling the social determinants of oral health inequalities. Community Dent Oral Epidemiol 2007 Feb; 35(1): 1-11.

23. Watt $\mathrm{R}$, Sheiham A. Integrating the common risk factor approach into a social determinants framework. Community Dent Oral Epidemiol 2012 Aug; 40(4): 289-296. 
24. Cangussu MCT, Castellanos RA, Pinheiro MF, Albuquerque SR de, Pinho C. Cárie dentária em escolares de 12 e 15 anos de escolas públicas e privadas de Salvador, Bahia, Brasil, em 2001. Pesqui Odontol Bras 2002; 16(4): 3793-84.
25. da Fonseca MA, Avenetti D. Social determinants of pediatric oral health. Dent Clin North Am 2017 Jul; 61(3): 519-532.ficado [Internet]. New York: PNUD; 2013 [cited 2013 Dec 18]. 224 p. Available from: http://hdr.undp.org/sites/default/files/ hdr2013_portuguese.pdf 